\title{
Desenvolvimento de crianças sob influência dos contextos sociais e da religiosidade
}

Lesly Guimarães Vicenzi de Oliveira

Janari da Silva Pedroso

\section{RESUMO}

0 artigo analisa a partir da psicologia psicodinâmica e da antropologia social o desenvolvimento de crianças sob influência dos contextos sociais e da religiosidade para compreender como o contexto ambiental e o apoio emocional influenciam no desenvolvimento. Trata-se de um estudo qualitativo que utiliza entrevistas semiestruturadas, observações e diário de campo. Participaram cinco crianças, com idades de cinco a seis anos, pais, cuidadores e professores. Os resultados foram sistematizados pela análise de conteúdo e apontaram uma circulação atravessada pela violência do bairro e influência religiosa das famílias na sociabilidade das crianças. Conclui-se que a circunstância do contexto social, que gerou medo e insegurança nos pais das crianças, e a prática religiosa dos cuidadores incidiram de modo significante no desenvolvimento emocional.

Palavras-chave: desenvolvimento infantil; crianças em idade escolar; ambientes sociais; religião.

\section{ABSTRACT}

\section{Child development under the influence of social and religious contexts}

The article analyses, based on psychodynamic psychology and social anthropology, the development of children under the influence of social and religious contexts in order to understand how environmental context and emotional support influence development. This qualitative study uses semi-structured interviews, observations, field journal. Five children aged five to six years, parents, caregivers and teachers participated. The results were organized by content analysis and showed a circulation crossed by neighborhood violence and religious influence of families the social skills of children. It is concluded that the circumstances of the social context which generated fear and insecurity in parents of the children, and religious practice of caregivers were significant to the emotional development.

Keywords: childhood development; school age children; social environments; religion.

A promoção de estudos sobre o desenvolvimento infantil a partir da perspectiva psicodinâmica e sob a análise antropológica da realidade social é necessária para asseverar sobre a influência das relações sociais no desenvolvimento emocional nos primeiros anos de vida. Nesta perspectiva, este estudo dialoga com a obra de Winnicott (1965/1990) a fim de analisar o desenvolvimento de crianças a partir do exame da constituição psíquica e do ambiente facilitador. Para tanto, o aporte conceitual sobre contexto está circunscrito no estudo das redes sociais (Bott, 1976; Mauss, 2001) discutidas a partir da antropologia das emoções (Koury, 2005; 2014).

Este trabalho organizou-se a partir de um estudo qualitativo, com a participação de cinco crianças e seus cuidadores, residentes em um bairro de periferia da cidade de Belém e que frequentavam uma escola com orientação religiosa (protestante). Considerou-se para análise os tempos de observação participante no ambiente escolar, no domicílio, no trajeto escolaresidência e nas atividades extras relatadas pelos pais e professores, no sentido de apreender

\section{Sobre os Autores}

L.G.V.

orcid.org/0000-0003-0194-4225

Universidade Católica de Brasília (UCB) - Brasília, DF

lesly_vicenzi@hotmail.com

J.N.P.

orcid.org/0000-0001-7602-834X

Universidade Federal do Pará

(UFPA) - Belém, PA

pedrosoufpa@gmail.com

\section{Direitos Autorais}

Este é um artigo de acesso aberto e pode ser reproduzido livremente, distribuído, transmitido ou modificado, por qualquer pessoa desde que usado sem fins comerciais. 0 trabalho é disponibilizado sob a licença Creative Commons CCBY-NC.

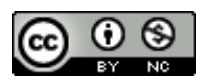




\section{-4* INTERACÃO EM IF PSICOLOGIA}

desses ambientes de sociabilidade das crianças as interações afetivas entre as pessoas e os contextos. A metodologia qualitativa triangulou instrumentos (entrevistas, observação, diários de campo) de coleta de dados e as orientações analíticas da psicologia (psicodinâmica) e antropologia, para compreensão dos contextos em que ocorriam as brincadeiras, a alimentação, a vida familiar e escolar, a rotina e a religiosidade, os quais foram imprescindíveis para o alcance das análises dos resultados.

Entendemos o desenvolvimento como um processo de maturação e acumulação de experiências de vida em um ambiente facilitador. A importância deste contexto é marcante para a trajetória do desenvolvimento humano e pode ser descrito em termos de dependência absoluta e dependência relativa rumo à independência (Winnicott, 1965/1990).

A compreensão da vida familiar incorpora o entendimento de Bott (1976) de que os indivíduos constroem seu meio ambiente, de acordo com suas necessidades conscientes e inconscientes. Para a autora (1976), o contexto das relações sociais permite compreender que:

O meio social imediato das famílias urbanas é mais bem compreendido, não como a área local em que vive a família, mas sim como a rede das relações sociais reais que elas mantêm, sem se considerar o fato de estarem confinadas à área local ou de se estenderem para além de suas fronteiras (p. 111).

O contexto urbano em que a família está inserida deve ser analisado como uma rede conexa com outros contextos ou grupos pelos quais as pessoas participam. Deste modo, as crianças não estão encapsuladas nas famílias, já que transitam por diversos lugares.

Nesta mesma direção, as crianças, ao circularem ou transitarem nas instituições sociais - tais como igreja, escola, entre outros - além da família, são influenciadas no que se refere ao seu desenvolvimento. Para Mauss (1974) trata-se de um controle sobre o corpo identificado nas práticas corporais que são transmitidas:

Cada sociedade impõe ao indivíduo um uso rigorosamente determinado de seu corpo [...] É por intermédio da educação das necessidades e das atividades corporais que a estrutura social imprime sua marca nos indivíduos. Adestram-se as crianças [...] a dominar reflexos [...] inibem-se medos [...] selecionam-se pausas e movimentos (p. 3).

No entendimento de Maus (1974) as instituições e, em especial, a religião possuem uma eficácia simbólica cujo poder de significação remete à magia como um veículo de comunicação e linguagem que pode ser compreendido nas
Lesly Guimarães Vicenzi de Oliveira e Janari da Silva Pedroso

análises das crianças quando circulam nos diferentes contextos.

\section{CIRCULAÇÃO DE CRIANÇAS E DESENVOLVIMENTO EMOCIONAL}

A criança se desenvolve emocionalmente no contato com seu meio ambiente físico e emocional, que possui um caráter dinâmico. Neste processo, a família pode não perceber que os cuidados com as crianças possuem caráter intermitente e fluido, com transferência de responsabilidade que nem sempre são reconhecidas pelos cuidadores, por existirem diversos contextos nos quais as crianças são inseridas cotidianamente (Motta-Maués, 2004; Motta-Maués, Igreja \& Dantas, 2009).

Motta-Maués, Igreja e Dantas (2009) salientam que a circulação como uma forma de deslocamento das pessoas entre vários contextos ou lugares ocorre todos os dias e mobiliza (muitas vezes para além da rede de parentesco) a busca de cuidados com as crianças, que inclui outros grupos, tais como a creche, a babá, ou outras atividades nas quais a criança participa e circula. Fonseca (1995) descreve a circulação de crianças enquanto conceito e refere que há uma transferência de responsabilidade pelos cuidados da criança de um adulto para outro.

O termo circulação de crianças sugere a necessidade de um olhar mais cuidadoso sobre as obrigações de parentesco, consanguinidade, afinidade e relações próximas de amizade que envolve a rede social da criança. Dentre as explicações que possibilitam o entendimento do conceito de circulação, destaca-se o funcionamento familiar e suas conexões externas em redes de apoio social e emocional. Deste modo, o cuidado liga-se à obrigação de parentesco, no qual o ato de cuidar de uma criança ou ampará-la sustenta-se em um sentimento de troca que aparece tanto nas relações familiares e de paraparentesco como no compadrio, que amplia o conceito de filiação ampliada ou de criação compartilhada (Motta-Maués, 2012).

Nos estudos de família, torna-se importante compreender as mudanças e nuances que ocorrem na circulação para o desenvolvimento das crianças. Fonseca (1995) descreve que a circulação de crianças não deve estar associada a um problema social e Serra (2003) entende este conceito como parte da diversidade social e do ciclo de vida familiar.

0 desenvolvimento emocional da criança se relaciona aos cuidados proporcionados pela adaptação ativa mãe-bebê e são materializados no estabelecimento de uma rotina. Os afazeres cotidianos com horários da alimentação, preparos repetitivos dos banhos, cheiros e experiências tecem um repertório de conhecimento que deixam o sujeito, ainda bebê, seguro em seu ambiente pelo reconhecimento ambiental que 


\section{-4: INTERACÃO EM LF PSICOLOGIA}

acaba por sustentar a subjetividade (Winnicott, 1965/1990; Winnicott, 1965/2005). Deste modo, reconhece- se que "o bebê rapidamente aprende a fazer uma previsão[...] Por enquanto, posso ficar seguro, esquecer o humor da mãe e ser espontâneo [...]" (Winnicott, 1953/1975, p. 159). A capacidade de aprendizagem e previsibilidade dos acontecimentos leva a integração na psique a partir do modo como a criança reconhece o ambiente com todos os estímulos, tais como cheiro, sons, movimentos, cores e pessoas presentes no contexto de cuidado (Winnicott, 1965/1990; Winnicott, 1965/2005; Pondé, 2011).

A importância do ambiente para o desenvolvimento emocional nos contextos de sociabilidade das crianças e as interações afetivas nas redes sociais deve ser considerada para além do grupo familiar. Para Winnicott (1953/1975) essa articulação entre desenvolvimento emocional e ambiente é apresentado como:

Chamo atenção para o fato de que não se pode fazer uma descrição do desenvolvimento emocional do indivíduo inteiramente em termos do indivíduo, mas considerando que em certas áreas - e essa é uma delas, talvez a principal - o comportamento do ambiente faz parte do próprio desenvolvimento pessoal do indivíduo e, portanto, tem de ser incluído (p. 79).

Reconhecemos que os movimentos em circulação enquanto a criança transita nos ambientes, em que cuidados e responsabilidades sobre elas são repassados de um adulto para outro, promovem o desenvolvimento considerando os diversos contextos no trato com as crianças (Motta-Maués, 2004; Oliveira \& Pedroso, 2014). Deste modo, as mudanças na sociedade e na família permitem que hoje as crianças passem a ter diversos cuidadores que facilitam o desenvolvimento e o compartilhamento do cuidado.

\section{DESENVOLVIMENTO EMOCIONAL: MODOS DE EXPERIENCIAR}

A relação entre desenvolvimento e as experiências organizadas pelo cuidador (familiar, professor, babá entre outros) apoia-se inicialmente nas necessidades básicas (alimentação, segurança) para outras demandas afetivas e sociais. Vale ressaltar que a satisfação das necessidades implica um modo de experienciar nos lugares em que a criança circula. Portanto, poderá haver diversos cuidadores, ou apenas um cuidador responsável pelos cuidados, que não necessariamente estão vinculados pelas relações de parentesco e consanguinidade (Bicalho, Lacerda \& Catafesta, 2008; Lima, Pedroso, Cruz \& Aguiar, 2016).

Para Winnicott $(1953 / 1975)$ as experiências com o mundo formam o repertório, a subjetividade. Então, apreendese que o grupo social interfere bastante na forma como as crianças se desenvolvem, bem como no modo como os cuidadores acreditam que as crianças devem viver. Nesta perspectiva, Winnicott $(1965 / 2005)$ afirma o processo de desenvolvimento como:

O desenvolvimento, em poucas palavras, é uma função da herança de um processo de maturação e da acumulação de experiências de vida; mas esse desenvolvimento só pode ocorrer num ambiente propiciador. A importância deste ambiente propiciador é absoluta no início, e a seguir relativa; o processo de desenvolvimento pode ser descrito em termos de dependência absoluta, de dependência relativa e um caminhar rumo à independência (p. 19).

No princípio, o bebê não constitui uma unidade em si mesmo, pois há uma organização entre o indivíduo e o meio ambiente. Idealmente, a base da saúde mental é estabelecida nos primórdios da infância pelo provimento de cuidados dispensados à criança por aquilo que Winnicott conceitua acerca do termo "mãe suficientemente boa" ao descrever sobre o desenvolvimento emocional da criança. 0 bebê depende da disponibilidade de um adulto preocupado com os seus cuidados, isto é, que possa contribuir para um desenvolvimento que as necessidades da criança, que em princípio são absolutas, tornem-se adequadas e adaptadas ao alcance de metas, tais como integração, personalização e o desenvolvimento das relações objetais (Winnicott, 1965/1990; Santos, 1999). Winnicott (1953/1975) descreve que não se pode dissociar ambiente e indivíduo. Portanto, o ambiente pode ser entendido a partir de aspectos geográficos, socioeconômicos, culturais e afetivo-sociais.

Nos primórdios da vida de uma criança, é importante que nos seus primeiros contatos ela se sinta livre e tenha um quadro de referência internalizado que a possibilite pôr à prova a instituição parental. Uma criança se desenvolve no contexto familiar por meio dos cuidados recebidos e doados. Em decorrência da confiança de seu pai e de sua mãe, a criança põe à prova o seu poder de desintegrar, destruir, assustar, cansar, manobrar, consumir e apropriar-se. "Em suas origens, a agressividade é quase sinônimo de atividade: trata-se de uma função parcial" necessária para a formação da pessoa, a "agressividade faz parte da expressão primitiva do amor" e existe antes mesmo da integração da personalidade (Winnicott, 1958/2000, p. 289). Estes comportamentos são "normais" na infância, compõem as experiências do indivíduo e refletem nas suas ações presentes e futuras (Winnicott, 1984/2002).

As experiências emocionais são individuais e são "sentidas e vividas por um ator social específico, são produtos relacionais entre os indivíduos e a cultura e sociedade" (Koury, 2005, p. 319). Por meio dos cuidados, constrói-se a vida emocional do sujeito no ambiente. Hoyos 


\section{-4: INTERACÃO EM LF PSICOLOGIA}

(2006) afirma que a forma de cuidar é passada através das gerações, nas trocas de experiências e percepções que são mediadas pela cultura. Portanto, as emoções e pensamentos são incorporados no indivíduo por meio de símbolos, construídos e negociados publicamente (Costa \& Pereira, 1995).

Winnicott (1965/1990; 1953/1975) frisa o papel do ambiente e do contexto social para o desenvolvimento emocional da criança e define que as dificuldades experimentadas desde o início da infância e a forma como as crianças e adultos lidam com as situações vivenciadas apontam sobre a saúde psíquica futura. "É O ambiente circundante que torna possível o crescimento de cada criança; sem uma confiabilidade ambiental mínima, o crescimento pessoal da criança não pode se desenrolar, ou desenrola-se com distorções" (Winnicott, 1965/2005, p. 29). Nesse sentido, acredita-se que é preciso observar o ambiente e os cuidados vivenciados pelas crianças para compreensão do desenvolvimento emocional.

\section{CAMINHOS EM DESENVOLVIMENTO: TRAJETÓRIAS DE PESQUISA}

Entendemos que a subjetividade humana se constitui a partir das relações com ambiente, com as pessoas e consigo mesmo em uma trajetória de circulação. É uma condição reflexiva de seu ato. Tal compreensão assume um caráter ativo que orienta as indagações do estudo para a compreensão do desenvolvimento de crianças sob a responsabilidade dos diferentes cuidadores. Deste modo, indagamos: Quem são estes cuidadores? Que percepções possuem acerca do desenvolvimento e da circulação de crianças nos diferentes ambientes?

Dada a complexidade do campo de pesquisa, fez-se necessário a apropriação dos conceitos antropológicos, de circulação de crianças e redes sociais, e psicológicos, como desenvolvimento emocional, que orientou a utilização de vários instrumentos metodológicos (entrevistas, observação em grupo focal, diários de campo), no intuito de investigar e analisar o objeto de pesquisa. A perspectiva proposta por Mauss (2001) permitiu organizar os fatos de um contexto desconhecido, qual seja, a cultura presente na circulação de crianças que transitam em diferentes ambientes.

A coleta de dados foi realizada por meio de entrevista semiestruturada (Flick, 2009), entrevista grupal ou grupo focal (Barbour, 2009; Flick, 2009), observação participante (Angrosino, 2009; Flick, 2009) e diário de campo. Os dados coletados pelos instrumentos de pesquisa permitiram a produção de insights para uma análise triangulada com as orientações teóricas e metodológicas na discussão dos dados, que garantiu comparações instrutivas (Angrosino,
2009; Barbour, 2009; Turato, 2003).

A entrevista semiestruturada apresentou questionamento sobre a criança e os cuidadores, nos seguintes aspectos: rotina de cuidados; desenvolvimento físico e emocional; relações sociais; laços de afinidade e interesse, dentre outros. A observação da rotina diária destas cinco crianças foi importante na presente pesquisa, visto que ampliou o olhar do pesquisador sobre os aspectos culturais da infância dentro de um contexto inter-relacional onde a troca entre pares faz circular a reciprocidade e constituiu-se em subjetividade (Mauss, 2008).

As apreensões internas e externas da observadora também foram transcritas. De acordo com Mauss (2008), o pesquisador apreende a realidade se colocando no lugar do nativo, com as suas próprias impressões. As sensações da observadora foram transcritas não só no contato com o local e com os sujeitos, mas nas idas e vindas quando ela estava ausente do campo de pesquisa.

Para tanto, utilizou-se o diário de campo para um registro das percepções e sensações da pesquisadora. Malinowiski (1967) registrava em seu diário o sentimento vivido na experiência da pesquisa de campo, seu desânimo, dúvidas e vontade de fugir do local da pesquisa nem que fosse por meio de pensamentos. Sentimento este que não divergiu da apreensão da pesquisadora diante do contato com os participantes. Além das observações, anotaram-se ideias, frases e desenhos dos locais.

O procedimento de pesquisa iniciou-se com a submissão e aprovação pelo Comitê de Ética em Pesquisa com Seres Humanos, que orienta o sigilo dos dados pessoais dos participantes (nomes fictícios). Em seguida foi solicitada a permissão da direção da escola e, por fim, os participantes assinaram o Termo de Consentimento Livre e Esclarecido. As entrevistas individuais foram feitas com dupla de pais elou responsáveis de cinco crianças do primeiro ano do ensino fundamental e com a professora da respectiva série, no intuito de apreender a realidade percebida, a partir de narrativas individuais. Essa etapa foi importante para fortalecer o encontro entre o pesquisador e os entrevistados e para elucidar o tema da pesquisa (Flick, 2009).

A estruturação dos dados deu-se a partir da escolha da análise de conteúdo de Bardin (1977/2010) que permitiu a construção de categorias (violência e o sentimento de medo, sentimento de pertencimento e a religiosidade) por meio do acesso aos significados manifestos e latentes sobre o olhar destes cuidadores, produzidas na entrevista individual, entrevista grupal e observação. 


\section{-4* INTERACÃO EM LF PSICOLOGIA}

\section{VIOLÊNCIA E O SENTIMENTO DE MEDO}

Entre as diversas questões suscitadas tanto nas observações quanto nas entrevistas individuais e no grupo focal, destaca-se que $o$ que parece mais afetar o desenvolvimento emocional e a circulação das crianças foi o medo de transitar livremente pelos espaços, dado o aumento considerável da violência presente na cidade e no bairro em que viviam. 0 medo como um afeto humano pode causar impacto tanto no psiquismo quanto no cotidiano da pessoa. No dia a dia averígua-se a potência dessa afetividade dada a quantidade e grau de restrições que o sujeito se impõe, mobilizando ou imobilizando a vida (Pondé, 2011). "O medo é explicado pelo imaginário da violência urbana sobre o orbe pessoal e familiar" (Koury, 2009, p. 407).

Diante da impossibilidade de andar livremente pelo bairro por medo do que imaginam que possam ocorrer, os cuidadores se defendem da ameaça mudando as estratégias na circulação destas crianças. A preocupação com o entorno do bairro mobiliza os responsáveis por alternativas seguras. Uma opção garantida de todos os cuidadores foi pelos programas televisivos e pelo computador, meios de comunicação que participam do cotidiano de todas as crianças. O pai das gêmeas Pâmela e Susie ressalta: “... não gosto que elas brinquem em frente de casa, um dia estava com elas e fui assaltado por um moleque com faca..." e a mãe de Nilson assinala: "... não gosto que eles olhem pela janela, um dia em frente da igreja do lado de minha casa um homem foi morto, baleado...". A avó de Carlos ressalta "... um dia ele estava na casa de um vizinho (primo) e quando cheguei eles estavam vendo aquelas porcarias...". O ato de ficar dentro de casa, para os pais, é a presentificação do medo - fruto da violência.

0 medo da violência pode desencadear um cuidado de manter as crianças à parte do mundo e vigiadas, visto que o acesso à internet é restrito aos joguinhos infantis, DVD'S da Disney, livros religiosos e gibis do "clubinho", bem como o contato com outras crianças da vizinhança se torna limitado, apenas em raros momentos por entre as grades das casas. Da mesma forma tentam estreitar ao máximo a rede, para que a criança tenha pouco acesso a outras realidades não desejadas e escolhem a igreja e a escola como alternativas de controle e proteção. Koury (2009) em sua pesquisa sobre o medo na cidade de João Pessoa relata que no imaginário dos indivíduos encontra-se uma espécie de ponto de estrangulamento e fragmentação da rede de reconhecimento e sociabilidade. Na cidade a circulação de pessoas é tão grande que não se pode definir quem são estes transeuntes, gerando desconfiança, insegurança e receio, que estar próximo do outro se transforma em uma ameaça dado o desconhecimento.
O que Koury (2009) relata não difere do sentimento de diferença e estranhamento que os participantes da pesquisa possuem em relação aos seus próximos. A mãe de Nilson expõe que as formações da moral e do caráter são importantes para formação educacional e completa, "... meus meninos uma vez vinheram (sic) falando palavrão só de jogar bola um minuto na frente da casa quando falava com minha sogra...". A mãe de Carla afirma: "às vezes as crianças sabem mais do que nós!... Não deixo Carla brincar com estes primos... Tem um monte de moleque aí do bairro que anda com eles". Neste trecho da fala, a entrevistada refere-se aos parentes que dividem o mesmo lote residencial (diário de campo).

Esta percepção as fazem ser diferentes nos cuidados com seus filhos, tanto que não os deixam brincar com os meninos da rua (notas da observação). 0 medo permanente leva as pessoas a "mudarem de hábitos nas comunicações interpessoais com desconhecidos, fechando-se em casa e evitando outras pessoas" (Koury, 2011, p. 476).

A partir dos relatos acima é possível identificar a falta de confiança nos vizinhos que impede estes responsáveis de deixar seus filhos brincarem na rua, mesmo sendo o vizinho da mesma família. Isto é fruto da insegurança e do medo, dada a ameaça do desconhecido. A privação de experiências diversas leva ao desenvolvimento de patologias e dificuldades em relacionamentos interpessoais na criança, mas aludimos o fato de os cuidadores também sofrerem emocionalmente diante as próprias amarras e escolhas feitas no cuidado que, ao se depararem totalmente perdidos, logo depositaram na figura da pesquisadora uma esperança para resolução de suas ansiedades.

Mauss (2001) acrescenta que, de acordo com épocas e lugares, a sociedade fabrica estereótipos e modelos de comportamentos que se inscrevem no corpo. Limita-se a dor, a excitabilidade e a resistência de acordo com cada cultura, que é aprovada ou desaprovada coletivamente e não em funções particulares. 0 uso rigoroso do corpo fabrica máscaras sociais e, por meio da educação das necessidades e das atividades corporais, as estruturas sociais imprimem marcas nos indivíduos.

Bott (1976) considera que é mais fácil o indivíduo interiorizar normas quando vive em grupos do que quando vive em redes. Os participantes certamente fizeram escolhas não tão individuais quanto parecem, eles fizeram escolhas através de suas redes de relacionamento, optaram por malhas tão estreitas quanto grupos, tais como aldeias tribais tão pequenas e restritas que as diferenças são percebidas como afronta e reagem com agressividade e/ou fuga, posto que "os outros" põem em risco a ordem moral por eles propostas. 


\section{W'INTERACÃO EM ET PSICOLOGIA}

Diante do exposto é notório que a proteção destas famílias não se encontra só em relação ao grupo de vizinhos vistos como amorais e violentos, mas dos familiares e parentes, mesmo que morem na mesma residência e que não comunguem da mesma orientação religiosa, e assim optaram por colocar seus filhos em uma escola religiosa do tipo protestante o que favorece distorções na percepção das crianças em relação a diferenças e adversidades sociais.

\section{SENTIMENTO DE PERTENCIMENTO E A RELIGIOSIDADE}

A religiosidade vivenciada tanto na escola quanto na igreja é uma possibilidade de sentimento de pertencimento, uma rede de apoio social, dado o aumento de violência na cidade. Surge como opção de recriar a vida cotidiana e amenizar angústias e ansiedades. Assim, o comportamento dos cuidadores se inter-relaciona com o círculo social. Existe, dessa forma, um sentimento de igualdade compartilhada nas ideias e crenças comuns.

Os sujeitos, ao sentirem-se membros do grupo religioso, reconhecem-se como irmãos e necessitam então de uma proteção sobrenatural para explicar o que ocorre à sua volta e amenizar a angústia que sentem. Buscam a religiosidade como forma de pertencer a um grupo e excluir-se do resto da sociedade.

A religiosidade passa a ser um elemento estruturante da subjetividade, pois todos os dias as crianças oravam na escola, agradeciam pela manhã, pelo amigo, por tudo, além de orarem em casa, com seus pais, conforme visto na casa de Nilson (diário de campo).

Apreende-se que isto ocorre porque a religião traz regulamentos que regem a vida em comunidade, impondo limites às satisfações sexuais ou agressivas, mediante a humanização imaginária da morte e da natureza. 0 indivíduo encontra condições inacessíveis para pensar (Mauss, 2001).

0 pai das participantes gêmeas declara que suas ideias em relação ao cuidado de crianças estão baseadas em valores, ensinamentos e princípios cristãos. Inclusive, cita um episódio em que suas filhas viram pela fechadura vídeos pornôs de seu irmão, fato que o deixa irritado diante das atitudes do filho e atento perante as meninas, que não podem ter acesso aos conteúdos sexuais e muito menos contato com o menino que "... não foi batizado..." (notas da entrevista). Assim, o fato de o filho não comungar do mesmo princípio religioso faz o pai crer que ele ameace de alguma maneira o bem-estar moral das irmãs.

Os cuidadores, ao encontrar suporte solidário na sua rede de relações sociais, tendem a enfrentar problemas e sofrimentos com mais habilidade e segurança. Em verdade, "a realidade admitida como certa se solidifica para o homem na rua e no cotidiano"; a realidade emocional se constrói deste modo (Luckmann \& Berger, 2010, p.13).

Em relação aos cuidados dispensados por conta de princípios da religião, tem-se o exemplo da avó de Carlos, a qual descreve que foi curada de câncer de esôfago (notas da entrevista). O papel da religião no mundo civilizado e os fatores que impelem o sujeito a uma aceitação incrédula dos preceitos perpetrados pela figura divina são fatores que fazem o cuidador reproduzir, em todos os seus cuidados, o que acredita ser verdade. A partir deste entendimento, a religião reprime os instintos e os cerimoniais canalizam a energia reprimida, dando ao sujeito uma forma de suportar a realidade por meio de seus cuidados (Freud, 1913/1996).

A participante Pâmela discrimina seu colega de turma Marcelo por desenhar a imagem de Santa Nossa Senhora de Nazaré, padroeira da cidade. Ela e um grupo de amigos se irritam com o garoto que, para sentir-se pertencente ao grupo, risca o desenho e automaticamente é inserido novamente, inclusive elogiado pelos colegas. É nítido que o grupo possui uma coesão relacionada aos princípios morais e religiosos que, ao mesmo tempo em que os fazem crer em um sentimento de pertencimento, criam forças para "naturalizar as diferenças" no que julgam não se assemelhar a suas crenças e forma de existir e se relacionar.

As famílias e o grupo escolar que as crianças frequentam se organizam e coadunam das mesmas ideias sobre 0 cuidado de crianças. Isso porque se veem totalmente aterrorizados pelo mundo a sua volta, diante das trocas de informações do seu entorno como algo global ou um fato social total (Mauss, 2008). Esta situação acaba por se refletir emocionalmente no sujeito em desenvolvimento, o qual passa a crer que tudo aquilo que difere do seu grupo deve ser distanciado, portanto naturaliza-se a desigualdade.

\section{CONCLUSÃO}

A pesquisa analisou o desenvolvimento de crianças a partir da circulação nos contextos por onde elas transitam. A triangulação teórica permitiu uma compreensão das percepções dos cuidadores e das relações sociais dos participantes envolvidos no estudo. As teorias dos antropólogos (Maus, Bott, Koury) e de Winnicott permitiram uma análise relacional entre desenvolvimento emocional e circulação de crianças pelos ambientes (escola, casa, rua, igreja).

Em relação aos participantes, notou-se que a opção feita pelos cuidadores de quais locais as crianças podem ou não transitar sob seus cuidados, esteve diretamente relacionada com o modo como apreendem a realidade social. No caso da presente pesquisa, o medo da violência do bairro apresentou- 


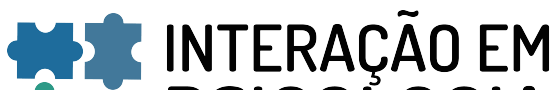 ET PSICOLOGIA}

se como pano de fundo para as escolhas realizadas.

Diante da violência, a opção religiosa foi condição facilitadora e possibilitou uma proteção para as dificuldades encontradas no entorno do bairro, considerado por seus cuidadores como violento e desfavorável para o desenvolvimento emocional de suas crianças. O apoio do grupo escolar religioso, neste caso, tornou-se fundamental para amenizar ansiedades e possibilitar a circulação dos cuidadores por outros espaços longe das crianças. Mas esta forma de se relacionar apontou para um impacto no que compreende a aceitação das diversidades, o que por vezes apareceu como naturalização das diferenças.

\section{CONTRIBUIÇÃO DE CADA AUTOR}

Pesquisa e escrita feitos por L.G.V.O. e J.S.P.

\section{DECLARAÇÃO DE CONFLITOS DE INTERESSES}

Os autores declaram que não há conflitos de interesses no presente artigo.

\section{REFERÊNCIAS}

Angrosino, M. (2009). Etnografia e observação participante. Rio de Janeiro: Artmed.

Barbour, R. (2009). Grupos focais. Rio de Janeiro: Artmed.

Bardin, L. (2010). Análise de conteúdo (L. A. Reto, \& A Pinheiro, Trad.). Lisboa, Portugal: Edições 70. (Trabalho original publicado em 1977).

Bicalho, C., Lacerda, M., \& Catafesta, F. (2008). Refletindo sobre quem é o cuidador familiar. Cogitare Enfermagem, 13, 118-123. doi: https://dx10.5380/ce. v13i1.11972

Bott, E. (1976). Família e rede social. Rio de Janeiro: Francisco Alves.

Costa. L. A. F. da, \& Pereira, A. M. (1995). Expressão de tristeza em camada popular urbana de Salvador, Bahia, Brasil. Cadernos de Saúde Pública, 11, 448-455. doi: https://dx10.1590/S0102-311X1995000300020

Flick, U. (2009). Introdução à pesquisa qualitativa. Rio de Janeiro: Artmed.

Fonseca, C. L. (1995). Caminhos da adoção. São Paulo: Cortez.

Freud, S. (1996). Totem e tabu. In J. Salomão (Org.), Edição standard brasileira das obras psicológicas completas de Sigmund Freud (J. O. de A. Abreu, Trad., Vol. 12, pp. 11191). Rio de Janeiro: Imago. (Trabalho original publicado em 1913).
Hoyos, D. M. G. (2006). Educar para el cuidado materno perinatal: una propuesta para reflexionar. Revista Hacia la Promoción de la Salud, 11, 81-93.

Koury, M. G. P. (2005). A antropologia das emoções no Brasil. RBSE - Revista Brasileira de Sociologia da Emoção, 4(12), 314-328.

Koury, M. G. P. (2009). O que é medo? Um adentrar no imaginário dos habitantes da cidade de João Pessoa, Paraíba. Psicologia \& sociedade, 21, 402- 410. doi: https://dx10.1590/S0102-71822009000300014

Koury, M. G. P. (2011). Medos urbanos e mídia: o imaginário sobre a juventude e violência no Brasil atual. Revista Sociedade e Estado, 26, 471-486. doi: 10.1590/S010269922011000300003

Koury, M G. P. (2014). Pela consolidação da sociologia e da antropologia das emoções no Brasil. Sociedade e Estado, 29, 841-866. doi: 10.1590/S0102-69922014000300009

Lima, F. T. I, Pedroso, J. da S., Cruz, E. J. S. da, \& Aguiar, L. F. (2016). Mothers and grandmothers in social vulnerability: conceptions about care and institutional shelter. Interpersona: an International Journal on Personal Relationships, 10(supp.1), 10-21. doi: https://dx10.5964/ijpr.v10isupp1.234

Luckmann, T., \& Berger, P. L. (2010). A construção social da realidade. Petrópolis: Vozes.

Malinowski, B. (1967). Um diário no sentido estrito do termo. Rio de Janeiro: Record.

Mauss, M. (1974) Sociologia e Antropologia. São Paulo: EPUEDUSP.

Mauss, M. (2001). Ensaios de sociologia. São Paulo: Perspectiva.

Mauss, M. (2008). Ensaio sobre a dádiva. Lisboa: Edições 70.

Motta-Maués, M. A. (2004). Na "casa da mãe"/na "casa do pai": anotações (de uma antropóloga e avó) em torno da "circulação" de crianças. Revista de Antropologia, 47, 427452. doi: https://dx10.1590/S0034-77012004000200003

Motta-Maués, M. A., Igreja, D. G. L., \& Dantas, L. M. S (2009). De casa em casa, de rua em rua... na cidade: "circulação de crianças", hierarquias e espaços sociais em Belém. Antropolítica: Revista Contemporânea de Antropologia, 26, 1-19.

Motta-Maués, M. A. (2012). Uma mãe leva a outra (?): práticas informais (mas nem tanto) de "circulação de crianças" na Amazônia. Scripta Nova: Revista Electrónica de Geografia y Ciencias Sociales, 16(395), 1-9.

Oliveira, L. G. V. de, \& Pedroso, J. da S. (2014). O olhar do cuidador sobre o desenvolvimento emocional de criança em circulação. Revista Brasileira de História \& Ciências Sociais, 6(11), 73-83. 


\section{N"INTERACÃO EM IT PSICOLOGIA}

Pondé, D. Z. F. (2011). O conceito de medo em Winnicott. Winnicott e-prints, 6(2), 82-131.

Santos, M. A. dos. (1999). A constituição do mundo psíquico na concepção winnicottiana: Uma contribuição à clínica das psicoses. Psicologia: Reflexão e Crítica, 12, 603-625. doi: https://dx10.1590/S0102-79721999000300005

Serra, M. M. P. (2003). Algumas considerações sobre a circulação de crianças e sua distribuição por regiões. Revista Brasileira de Estudos Populacionais, 20(2), 229239 .

Turato, E. R. (2003). Tratado de metodologia da pesquisa clínico-qualitativa: construção teórico-epistemológica discussão comparada e aplicação nas áreas da saúde e humana. Rio de Janeiro: Vozes.

Winnicott, D. W. (1975). O brincar e a realidade. Rio de Janeiro: Imago. (Trabalho original publicado em 1953).
Winnicott, D. W. (1990). O ambiente e os processos de maturação. Porto Alegre: Artes Médicas. (Trabalho original publicado em 1965).

Winnicott, D. W. (2000). Da Pediatria à Psicanálise: Obras escolhidas. Rio de Janeiro: Imago (Trabalho original publicado em1958).

Winnicott, D. W. (2002). Privação e delinquência. São Paulo: Martins Fontes. (Trabalho original publicado em 1984).

Winnicott, D. W. (2005). A família e o desenvolvimento individual. São Paulo, SP: Martins Fontes. (Original publicado em 1965).

Recebido em: 22/04/2016

Primeira decisão editorial em: 28/11/2016 Aceito em: 11/04/2017 